\title{
Correction to: A systematic review of necrotising fasciitis in children from its first description in 1930 to 2018
}

\author{
Arne Schröder ${ }^{1}$, Aurélie Gerin ${ }^{2}$, Gregory B. Firth ${ }^{3}$, Kelly S. Hoffmann ${ }^{4,5}$, Andrew Grieve ${ }^{5}$ and \\ Christina Oetzmann von Sochaczewski, ${ }^{5,6^{*}}$
}

\section{Correction to: BMC Infect Dis https://doi.org/10.1186/s12879-019-3941-3}

After publication of the original article [1], we were notified that two of the author names were incorrectly displayed in the pdf version of the paper, while one other name was incorrectly tagged in the XML version. Below you can find the changes:

- Arne Schrö should be replaced with Arne Schröder

- Aurelié Gerin should be replaced with Aurélie Gerin

- Oetzmann von Sochaczewski should be tagged as the full family name for Christina Oetzmann von Sochaczewski

The original article has been corrected.
Received: 18 April 2019 Accepted: 18 April 2019

Published online: 27 May 2019

\section{Reference}

1. Schröder, et al. A systematic review of necrotising fasciitis in children from its first description in 1930 to 2018. BMC Infect Dis. 2019;19:317. https://doi. org/10.1186/s12879-019-3941-3.

\section{Author details}

${ }^{1}$ Klinik für Anästhesiologie und Intensivmedizin, Marienkrankenhaus

Bergisch-Gladbach, Dr.-Robert-Koch-Straße 18, 51465 Bergisch-Gladbach, Germany. ${ }^{2}$ Department of Paediatrics, Chris Hani Baragwanath Academic Hospital, Faculty of Health Sciences, University of the Witwatersrand, 26 Chris Hani Road, Johannesburg ZA-1860, South Africa. ${ }^{3}$ Department of Orthopaedic Surgery, Chris Hani Baragwanath Academic Hospital, Faculty of Health Sciences, University of the Witwatersrand, 26 Chris Hani Road, Johannesburg ZA-1860, South Africa. ${ }^{4}$ Department of Paediatric Surgery, Universitair Medisch Centrum Groningen, Hanzeplein 1, Groningen NL-9713, The Netherlands. ${ }^{5}$ Department of Paediatric Surgery, Chris Hani Baragwanath Academic Hospital, Faculty of Health Sciences, University of the Witwatersrand, 26 Chris Hani Road, Johannesburg ZA-1860, South Africa. ${ }^{6}$ Klinik und Poliklinik für Kinderchirurgie, Universitätsmedizin Mainz, Langenbeckstraße 1, 55131 Mainz, Germany.

\footnotetext{
* Correspondence: c.oetzmann@gmail.com

${ }^{5}$ Department of Paediatric Surgery, Chris Hani Baragwanath Academic

Hospital, Faculty of Health Sciences, University of the Witwatersrand, 26 Chris

Hani Road, Johannesburg ZA-1860, South Africa

${ }^{6}$ Klinik und Poliklinik für Kinderchirurgie, Universitätsmedizin Mainz,

Langenbeckstraße 1, 55131 Mainz, Germany

Full list of author information is available at the end of the article
}

(c) The Author(s). 2019 Open Access This article is distributed under the terms of the Creative Commons Attribution 4.0 International License (http://creativecommons.org/licenses/by/4.0/), which permits unrestricted use, distribution, and reproduction in any medium, provided you give appropriate credit to the original author(s) and the source, provide a link to the Creative Commons license, and indicate if changes were made. The Creative Commons Public Domain Dedication waiver (http://creativecommons.org/publicdomain/zero/1.0/) applies to the data made available in this article, unless otherwise stated. 